\title{
Formation of Simple Nitriles upon Glucosinolate Hydrolysis Affects Direct and Indirect Defense Against the Specialist Herbivore, Pieris rapae
}

\author{
Roland Mumm • Meike Burow • \\ Gabriella Bukovinszkine'Kiss • Efthymia Kazantzidou • \\ Ute Wittstock • Marcel Dicke • Jonathan Gershenzon
}

Received: 6 March 2008 /Revised: 30 July 2008 / Accepted: 13 August 2008 /Published online: 12 September 2008

(C) The Author(s) 2008. This article is published with open access at Springerlink.com

\begin{abstract}
The glucosinolate-myrosinase system, found in plants of the order Brassicales, has long been considered an effective defense system against herbivores. The defensive potential of glucosinolates is mainly due to the products formed after myrosinase-catalyzed hydrolysis upon tissue damage. The most prominent hydrolysis products, the isothiocyanates, are toxic to a wide range of organisms, including herbivorous lepidopterans. In contrast, little is known about the biological activities of alternative hydrolysis products such as simple nitriles and epithionitriles that are formed at the expense of isothiocyanates in the presence of epithiospecifier proteins (ESPs). Here, we used transgenic Arabidopsis thaliana (Brassicaceae) plants overexpressing ESP (35S:ESP plants) to investigate the effects of simple nitriles on direct and indirect defense against the specialist cabbage white butterfly Pieris rapae L. (Lepidoptera, Pieridae). In the 35S:ESP plants, glucosinolates are hydrolyzed mainly to simple nitriles upon tissue disruption, while isothiocyanates are the predominant hydrolysis products in Columbia-0 (Col-0) wild-type plants. The parasitoid Cotesia
\end{abstract}

R. Mumm $(\bowtie) \cdot$ G. Bukovinszkine'Kiss $\cdot$ M. Dicke

Laboratory of Entomology, Wageningen University,

P.O. Box 8031, $6700 \mathrm{EH}$ Wageningen, The Netherlands

e-mail: roland.mumm@wur.nl

M. Burow $\cdot$ E. Kazantzidou $\cdot$ U. Wittstock $\cdot$ J. Gershenzon Department of Biochemistry,

Max Planck Institute for Chemical Ecology, Beutenberg Campus,

Hans-Knöll-Strasse 8,

07745 Jena, Germany

\section{Burow $\cdot$ U. Wittstock}

Institut für Pharmazeutische Biologie,

Technische Universität Braunschweig,

Mendelssohnstrasse 1,

38106 Braunschweig, Germany rubecula (Hymenoptera, Braconidae), a specialist on $P$. rapae larvae, was significantly more attracted to $P$. rapaeinfested 35S:ESP plants than to $P$. rapae-infested Col-0 wild-type plants in a wind tunnel setup. Furthermore, female $P$. rapae butterflies laid more eggs on Col-0 wild-type plants than on 35S:ESP plants when the plants had been damaged previously. However, when given a choice to feed on $35 \mathrm{~S}$ : ESP or Col-0 plants, caterpillars did not discriminate between the two genotypes. Growth rate and developmental time were not significantly different between caterpillars that were reared on 35S:ESP or Col-0 plants. Thus, the production of simple nitriles instead of isothiocyanates, as catalyzed by ESP, can promote both direct and indirect defense against the specialist herbivore P. rapae.

Keywords Glucosinolate - Epithiospecifier protein · Arabidopsis thaliana $\cdot$ Nitrile $\cdot$ Isothiocyanate Insect performance $\cdot$ Pieris rapae Oviposition preference . Cotesia rubecula $\cdot$ Indirect defense

\section{Introduction}

The glucosinolate-myrosinase system is one of the bestcharacterized antiherbivore defenses in the plant kingdom. Common to all families of the Brassicales order, it is found in agriculturally important Brassica crops and the model plant Arabidopsis thaliana (Fahey et al. 2001; Wittstock and Halkier 2002; Kliebenstein et al. 2005; Grubb and Abel 2006; Halkier and Gershenzon 2006). The system consists of glucosinolates, a group of amino acid-derived thioglucosides and myrosinases (thioglucoside glucohydrolases, EC 3.2.1.147) that hydrolyze the thioglucosidic bond of the glucosinolates yielding glucose and an unstable aglucone 


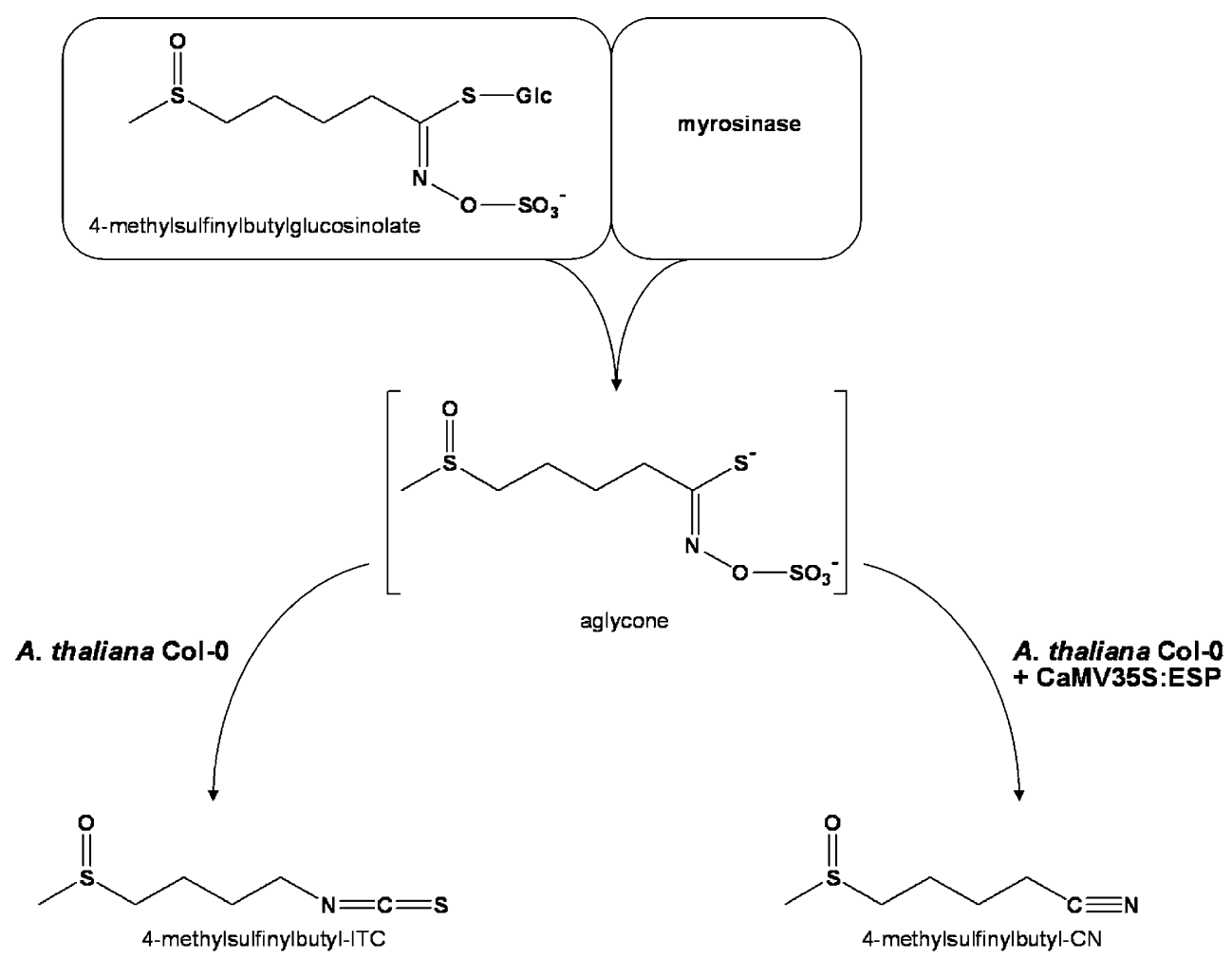

Fig. 1 Glucosinolate hydrolysis in A. thaliana Col-0 wild-type and 35S:ESP plants as shown for 4-methylsulfinylbutylglucosinolate, the main glucosinolate found in the Col-0 ecotype. Glucosinolates and their hydrolytic enzymes, the myrosinases, are stored in different cells in intact plant tissue. Damage to the tissue results in myrosinasecatalyzed hydrolysis of glucosinolates yielding glucose and unstable

(Fig. 1) (Rask et al. 2000). Spontaneous rearrangement of the aglucone then leads to the formation of an isothiocyanate. Under the influence of specifier proteins that are present in many glucosinolate-containing plants including Brassica napus and some Arabidopsis accessions, alternative products such as simple nitriles and epithionitriles are formed at the expense of isothiocyanates (Bernardi et al. 2000; Foo et al. 2000; Lambrix et al. 2001; Wittstock and Burow 2007). Glucosinolate hydrolysis in intact plant tissue is prevented by spatial separation of glucosinolates and myrosinases through storage in different cells and thus occurs only upon tissue disruption, e.g., by a feeding herbivore (Andréasson and Jørgensen 2003).

The glucosinolate-myrosinase system is involved in defense responses against herbivorous insects of different feeding guilds (Kliebenstein et al. 2002; Agrawal and Kurashige 2003; Wittstock et al. 2003; Kliebenstein 2004; Mewis et al. 2005; Barth and Jander 2006; Kim and Jander 2007). Its role in direct defense has been attributed mainly to the isothiocyanates, which are the predominant hydrolysis products in many plant species. Isothiocyanates are toxic upon ingestion, contact, or when present in the gas phase (Agrawal and Kurashige 2003; Wittstock et al. 2003). aglucones. In the ecotype Col-0, these aglucones predominantly rearrange into isothiocyanates due to the absence of a functional epithiospecifier protein. Expression of ESP from the Arabidopsis ecotype Ler under the control of the constitutive CaMV35S promoter results in nitrile formation upon leaf damage

However, the glucosinolate-myrosinase system appears to differentially affect specialist and generalist herbivores (Giamoustaris and Mithen 1995; Li et al. 2000). Several specialist insects have developed counteradaptations to circumvent the toxic effects of glucosinolates and their hydrolysis products (Müller et al. 2001; Alibadi et al. 2002; Ratzka et al. 2002; Wittstock et al. 2004; Agerbirk et al. 2006; Vergara et al. 2006; Wheat et al. 2007). Moreover, glucosinolates and isothiocyanates often serve as attractants or oviposition and feeding stimulants for these insects (Van Loon et al. 1992; Huang and Renwick 1994; Wittstock et al. 2003; Miles et al. 2005; Schoonhoven et al. 2005; Renwick et al. 2006; Barth and Jander 2006; Smallegange et al. 2007). Still, several studies have shown negative correlations between the glucosinolate content of the diet and the larval performance of herbivorous insects specialized on Brassicaceae (Mewis et al. 2005, 2006; Gols et al. 2007, 2008; Kim and Jander 2007).

Little is known about the biological activities of hydrolysis products other than isothiocyanates. In general, simple nitriles are considered less toxic than isothiocyanates (Lambrix et al. 2001; Wittstock et al. 2003; Burow et al. 2006b). For example, larvae of the generalist Tricho- 
plusia ni (cabbage looper, Lepidoptera, Plusiinae) feed more, and larvae of the generalist Spodoptera littoralis (Egyptian cotton leafworm, Lepidoptera, Noctuidae) perform better on nitrile-producing Arabidopsis plants than on isothiocyanate-producing plants (Lambrix et al. 2001; Burow et al. 2006b; Zhang et al. 2006). Given that insect herbivores seem to suffer less from simple nitriles than from isothiocyanates, the ecological rationale for nitrile formation in the Brassicaceae is not easy to understand. Different scenarios can be drawn in which a plant may benefit from producing nitriles. For example, nitrile formation could be advantageous in direct and indirect defense against specialized herbivores. Direct plant defense negatively affects the feeding stages or the egg deposition of the herbivore, whereas indirect defense acts by recruiting natural enemies of the herbivore, such as predators and parasitoids (Hilker and Meiners 2002). Since isothiocyanates are often exploited as attractants, oviposition, or feeding stimulants by specialized herbivores (Rask et al. 2000; Renwick 2002; Wittstock et al. 2003; Renwick et al. 2006), plants that do not produce isothiocyanates upon damage may become less apparent to specialists. Alternatively, carnivorous insects such as predators and parasitoids may be differentially attracted by isothiocyanates and nitriles. A few studies have demonstrated that parasitoids are attracted to isothiocyanates (Titayavan and Altieri 1990; Pivnick 1993; Murchie et al. 1997; Bradburne and Mithen 2000; Reddy et al. 2002; Blande et al. 2007). However, parasitoid and predator performance is also known to correlate negatively with glucosinolate content (Harvey et al. 2003; Kazana et al. 2007; Gols et al. 2008). This negative relationship might favor a behavioral response of predators and parasitoids to plant volatiles that contain simple nitriles instead of isothiocyanates.

Because the glucosinolate-myrosinase system is an activated plant defense, the role of specific glucosinolate hydrolysis products is difficult to study in experimental settings. Plants that differ in the type of hydrolysis products they form often also differ in other properties such as glucosinolate content or myrosinase activity. The use of synthetic compounds alone or in mixtures to compare the defensive role of certain hydrolysis products also can be misleading due to differences in volatility. Moreover, many of them cannot be obtained as pure compounds. However, the availability of molecular tools to genetically manipulate model plants such as Arabidopsis provide an opportunity to overcome these difficulties (e.g., Degenhardt et al. 2003; Snoeren et al. 2007). The use of transgenic Arabidopsis lines that have been modified in glucosinolate hydrolysis provide a more natural system to compare the effects of naturally occurring relative and absolute amounts of members of different types of glucosinolate hydrolysis products.
Arabidopsis accessions differ in the type of glucosinolate hydrolysis products they produce upon tissue damage. This is due to allelic variation at the locus that encodes the epithiospecifier protein (ESP, Lambrix et al. 2001). For example, plants of the Landsberg erecta (Ler) accession possess a functional ESP gene and produce predominantly simple nitriles upon tissue disruption, while isothiocyanates are the major glucosinolate hydrolysis products of the Columbia-0 (Col-0) accession that lacks functional ESP (Lambrix et al. 2001). We used a transgenic line of Arabidopsis Col-0, which expresses the ESP cDNA from the Ler accession under the control of the CaMV35S promoter (35S:ESP plants; Burow et al. 2006b). In the 35S: ESP plants, glucosinolates are predominantly hydrolyzed to simple nitriles, whereas Col-0 wild-type plants mainly produce isothiocyanates upon damage (Burow et al. 2006b). For example, in Col-0 wild-type plants, the hydrolysis of 4-methylsulfinylbutylglucosinolate, the most abundant glucosinolate in the rosette leaves of this ecotype, leads to the formation of 4-methylsulfinylbutyl isothiocyanate. If ESP is overexpressed, however, the corresponding nitrile is produced (Fig. 1). However, neither the glucosinolate profile, the myrosinase activity levels, nor the morphology is altered in 35S:ESP plants compared with Col-0 wild type (Burow et al. 2006b).

In the present study, we used the 35S:ESP plants to investigate the role of simple nitriles in the interaction between Arabidopsis, the specialist cabbage white butterfly Pieris rapae L. (Lepidoptera, Pieridae), and its specialist larval endoparasitoid Cotesia rubecula (Marshall) (Hymenoptera, Braconidae). P. rapae is one of the most abundant butterflies in Northern and Central Europe and is neurophysiologically and biochemically adapted to using glucosinolate-containing plants as its sole hosts (Renwick 2002; Wittstock et al. 2004; Schoonhoven et al. 2005; Braby and Trueman 2006, and references therein). Most interestingly, caterpillars of $P$. rapae excrete simple nitriles in their feces (Agelopoulos et al. 1995) due to the action of a midgut nitrile-specifier protein that directs the hydrolysis of ingested glucosinolates from isothiocyanate towards simple nitrile formation (Wittstock et al. 2004; Burow et al. 2006a). P. rapae is able to complete its development on Arabidopsis (Van Loon et al. 2000; Harvey et al. 2007).

Volatiles of different plant species, including Arabidopsis, that are infested with $P$. rapae caterpillars are known to attract C. rubecula females (Agelopoulos and Keller 1994a; Geervliet et al. 1994, 1996; Van Poecke et al. 2001). The headspace of P. rapae-infested Arabidopsis plants contains nitriles that may originate from the frass of the caterpillars or the wounded plant tissue (Van Poecke et al. 2001; Van Poecke 2007; Wittstock et al. 2004). The feces of P. rapae caterpillars are attractive to $C$. rubecula from a distance, and their headspace contains predominantly nitriles (Agelopoulos 
et al. 1995; Wittstock et al. 2004). Electrophysiological studies have demonstrated that antennae of C. rubecula respond to certain isothiocyanates and nitriles (J.J.A. van Loon, unpublished results; Smid et al. 2002). Therefore, we used wind tunnel experiments to test whether Arabidopsis plants that overexpress ESP are more attractive to $C$. rubecula than the isothiocyanate-producing Col-0 wild-type plants.

Isothiocyanates are involved in long-distance host recognition by a number of specialized insect herbivores (reviewed in Wittstock et al. 2003). Therefore, we investigated whether the higher proportion of nitriles formed in $35 \mathrm{~S}: E S P$ plants as compared to wild-type plants influences the oviposition behavior of $P$. rapae butterflies. Glucosinolates stimulate egg deposition by $P$. rapae upon contact, but in nature butterflies might also be exposed to glucosinolate hydrolysis products, e.g., when host plants are already infested with feeding caterpillars (e.g., Huang et al. 1993, 1994). Additionally, we tested whether the feeding preference and performance of $P$. rapae differs between 35S:ESP plants and Col-0 wild-type plants. Despite the known glucosinolate detoxification mechanism in the midgut of $P$. rapae caterpillars, high concentrations of isolated isothiocyanates reduce $P$. rapae caterpillar growth and survival (Agrawal and Kurashige 2003). Combining these diverse bioassays, we aimed at obtaining a better insight into the contribution of nitriles to the relationships of $P$. rapae with its host plant and its enemies.

\section{Methods and Materials}

Plants A. thaliana Col-0 and the transgenic line 35S:ESP (2.6, T4; in the Col-0 background; Burow et al. 2006b) used for wind tunnel and oviposition experiments were grown from seed in soil (Lentse Potgrond, Cuijk, the Netherlands) in a controlled-climate room at $21 \pm 1^{\circ} \mathrm{C}$, a L8:D16-h photoperiod, $80-110 \mu \mathrm{mol} \mathrm{m}{ }^{-2} \mathrm{~s}^{-1}$ photosynthetically active radiation (PAR), and $55 \pm 5 \%$ relative humidity (RH). Two-week-old seedlings were transferred to pots (Teku, Pöppelmann, Lohne, Germany) containing the same soil. Plants used for the experiments were 4-6week-old and in the vegetative stage. Plants used to test the feeding preference and larval performance of $P$. rapae were grown under similar conditions for 4-5weeks except that the photoperiod was a L10:D14-h photoperiod and the relative humidity was $60 \pm 5 \%$.

Insects A continuous rearing of $P$. rapae for oviposition preference tests was maintained on Brussels sprouts plants in a climatized room at $21 \pm 1{ }^{\circ} \mathrm{C}, 60 \pm 10 \% \mathrm{RH}$ and an L16:D8-h photoperiod. P. rapae larvae used for feeding preference tests and larval performance tests were raised under similar conditions except that relative humidity was $75 \pm 5 \%$. The parasitoid C. rubecula was reared on P. rapae caterpillars feeding on Brussels sprouts plants in a greenhouse at $24 \pm 4^{\circ} \mathrm{C}, 60 \pm 20 \% \mathrm{RH}$, and a L16:D8h photoperiod. For experiments, $C$. rubecula pupae were collected and kept in a cage in a climate cabinet $\left(23 \pm 1^{\circ} \mathrm{C}\right.$, $60 \pm 10 \% \mathrm{RH}$, and L16:D8-h photoperiod). Emerging wasps were provided with water and honey. Male and female wasps were kept together until the experiment.

Plant Treatments for Parasitoid and Oviposition Experiments Plants were either artificially damaged or infested with ten first-instar $P$. rapae caterpillars. Plants were infested for $24 \mathrm{~h}$ and were kept in a climate chamber at $21 \pm 1^{\circ} \mathrm{C}$, a L8:D16-h photoperiod, $80-110 \mu \mathrm{mol} \mathrm{m} \mathrm{m}^{-2} \mathrm{~s}^{-1}$ photosynthetically active radiation, and $55 \pm 5 \% \mathrm{RH}$ until the experiments. Artificially damaged plants were obtained by punching a $\sim 7-\mathrm{mm}^{2}$ hole into each of six leaves of a plant right before the experiment. Intact Arabidopsis plants served as controls.

Wind Tunnel Experiments Behavioral choice experiments with the parasitoid $C$. rubecula were done with a wind tunnel setup $\left(25 \pm 1{ }^{\circ} \mathrm{C}, 60 \pm 10 \% \mathrm{RH}, 35 \mu \mathrm{mol} \mathrm{m} \mathrm{m}^{-2} \mathrm{~s}^{-1}\right.$ PAR) as described by (Geervliet et al. 1994). The wind speed was adjusted to $0.2 \mathrm{~m} \mathrm{~s}^{-1}$. Two-choice experiments were conducted by placing two odor sources each consisting of six Arabidopsis plants at the upwind end of the tunnel as described by Van Poecke et al. (2001). Naïve $C$. rubecula females (without oviposition experience) were separated from males $3 \mathrm{~h}$ prior to the experiment and transferred to another cage that was placed in the experimental room to acclimatize the parasitoids to the new environment. The wasps were individually introduced into the wind tunnel on Arabidopsis leaves of the treatments that they were also exposed to in the wind tunnel. These leaves were used in an alternating way, i.e., in the case that $P$. rapae-infested Col-0 wild-type was tested against caterpillar-infested 35S:ESP plants, the first, third, fifth, etc. wasp was introduced on an Col-0 wild-type leaf from which the caterpillars and their products had been carefully removed. Consequently, the second, fourth, sixth, etc. tested parasitoid was introduced on an 35S:ESP leaf from which the caterpillars and their products had been carefully removed as well. This increases the general behavioral response of the parasitoids to plant cues but likely does not induce a shift of preference (Kaiser and Cardé 1992; Bleeker et al. 2006; Smid 2006). Wasps were allowed to walk onto the leaves themselves. The leaf with the wasp was placed at the middle of the release cylinder, which was $60 \mathrm{~cm}$ downwind from the two odor sources. As soon as the parasitoid had left the leaf for a few seconds, the leaf was carefully removed with tweezers without 
disturbing the parasitoid. The flight behavior of the wasps was observed. Flights that resulted in a landing on one of the two odor sources were recorded as a "choice." Parasitoids that did not leave the release cylinder or landed on other parts of the wind tunnel within 10min were recorded as "no choice." Every parasitoid was used once. In order to correct for unforeseen asymmetry in the setup, the position of the odor sources was swapped after five tested parasitoids. After testing ten parasitoids, the odor sources were replaced with new ones. Every experiment was repeated at least five times over the course of several days. In order to check whether parasitoid discrimination was influenced by the amount of the caterpillar feeding, the leaf area removed by caterpillars from three infested Col- 0 wildtype plants and three 35S:ESP plants from three experimental days was analyzed using the program ImageJ $1.37 \mathrm{v}$ (http://rsb.info.nih.gov/ij/).

Oviposition Preference Test Freshly emerged P. rapae adults were transferred to a large cage $(67 \times 100 \times 75 \mathrm{~cm})$ in a greenhouse compartment at $24 \pm 4^{\circ} \mathrm{C}, 60 \pm 20 \% \mathrm{RH}$, and an L16:D8-h photoperiod. Butterflies were provided with $10 \%$ sucrose solution. Three to 5 days after emergence, one male and one female butterfly were transferred to each of the oviposition cages $(67 \times 50 \times 75 \mathrm{~cm})$ in the same greenhouse compartment. Each butterfly couple was also provided with a $10 \%$ sucrose solution. In addition to natural daylight, the cages were illuminated by sodium vapor lamps (SON-T, 500W, Philips, the Netherlands) from 10:00a.m. to 4:00p.m. At $48 \mathrm{~h}$ prior to the experiment, a single untreated Brussels sprouts leaf was placed in each cage as an oviposition substrate. After $6 \mathrm{~h}$, the leaf was removed. On the experimental day between 10:00a.m. and 11:00a.m., a transgenic 35S:ESP plant and a Col-0 wild-type plant were placed approximately $40 \mathrm{~cm}$ apart from each other in each cage. In one experiment, both plants were intact, and in a second experiment both plants were artificially damaged. $P$. rapae was allowed to lay eggs on the two plants for $5 \mathrm{~h}$. The plants were then removed, and the eggs laid were counted. The experiments were conducted in several cages at the same time and on several days per treatment, each replicate with new plants and butterflies.

P. rapae Feeding Preference Test Feeding choice tests were carried out in a climate chamber with an L16:D8-h photoperiod, $75 \pm 5 \% \mathrm{RH}$, and a temperature of $21 \pm 1^{\circ} \mathrm{C}$. For each replicate, three Col-0 plants and three 35S:ESP plants were alternately arranged in a circle. A single $P$. rapae third instar was released in the center of each arena at the level of the leaf rosettes, and the larvae were allowed to feed for $24 \mathrm{~h}$. A total of 18 replicates was carried out on three experimental days with independently grown sets of plants. Leaf areas removed from the three wild-type plants and the three $35 \mathrm{~S}$ :
ESP plants in each arena were measured. Leaf rosettes were digitally photographed with a reference mark before and after the experiments to calculate the removed leaf area using the program ImageJ 1.37v (http://rsb.info.nih.gov/ij/).

P. rapae Performance and Developmental Studies To compare the performance of P. rapae on the 35S:ESP plants and Col- 0 wild-type plants, larvae were reared from emergence to pupation on 5-week-old 35S:ESP plants in a climate chamber $\left(21 \pm 1^{\circ} \mathrm{C}, \mathrm{L} 16\right.$ :D8-h photoperiod, $75 \pm 5 \%$ relative humidity). Single newly emerged larvae ( $<24 \mathrm{~h}$ old $)$ were placed on individual plants that were then covered with perforated plastic bread bags to prevent insects from escaping. The weight of each larva was recorded on day 7 after hatching, when the larvae were transferred to fresh plants for the first time, and again on day 10. The larvae were transferred to new plants three to four times depending on their consumption rate. One to 2 days after pupation, the pupae were removed from the plants and placed individually in small ventilated plastic vessels. The emergence of adults was monitored every day for a period of 30 days.

Statistical Analysis In the wind tunnel experiments, a binomial test was used to analyze whether the behavioral choices of the parasitoids differed from a 50:50 distribution between the two odor sources. Parasitoids that did not make a choice were excluded from the statistical analysis. To check whether introducing the parasitoids on different leaves influenced the subsequent choice of the parasitoids, a McNemar test for marginal homogeneity was applied. In the oviposition choice tests, most individuals of $P$. rapae laid eggs on both the Col-0 wild-type and the 35S:ESP plant. The number of eggs on each treatment per individual were considered as a paired sample and were analyzed with the nonparametric Wilcoxon signed ranks test. In addition, we also analyzed the egg incidence by using a sign test. For the feeding choice experiments with P. rapae, the removed leaf area from each of the three Col-0 wild-type and the three 35S:ESP plants of each replicate were pooled, and a mean was calculated. A Wilcoxon signed ranks test was applied to test whether means were statistically different. Mann-Whitney $U$ tests were applied to test for differences in performance-related parameters between Col-0 wild-type and 35S:ESP plants. All tests are described by Glantz (2005), and for some tests the statistical software package SPSS 12.0.1 (SPSS Inc., Chicago, IL, USA) was used.

\section{Results}

Behavioral Response of C. rubecula to Volatiles of ESP Overexpressing and Wild-Type Arabidopsis Plants. P. 
rapae-caterpillar-infested 35S:ESP plants attracted more $C$. rubecula parasitoids than caterpillar-infested Col-0 plants in a two-choice wind tunnel setup (binomial test, $p<0.05$; Fig. 2). However, when artificially damaged before the experiment, 35S:ESP plants attracted significantly fewer parasitoids than caterpillar-infested Col-0 wild-type plants (binomial test, $p<0.05$; Fig. 2). When caterpillar-infested 35S:ESP plants were compared with artificially damaged ones, more parasitoids landed on the caterpillar-infested plants (binomial test, $p<0.005$; Fig. 2). However, artificially damaged 35S:ESP plants were more attractive to $C$. rubecula than intact plants of the same line (binomial test, $p<0.001$; Fig. 2). The introduction of the parasitoids to the wind tunnel on leaves of either Col-0 or 35S:ESP plants did not bias their subsequent choice but stimulated the general response of the wasps to plant volatiles (data not shown, McNemar test, $p>$ $0.05)$. The leaf area removed by the caterpillars did not differ between 35S:ESP and Col-0 wild-type plants (35S:ESP: $1.62 \pm 0.11 \mathrm{~cm}^{2}$, Col-0: $1.61 \pm 0.22 \mathrm{~cm}^{2}$; mean $\pm \mathrm{SE}, N=18$; Mann-Whitney U test, $p>0.4$ ).

Oviposition Preference of $\mathrm{P}$. rapae P. rapae lays individual eggs that are usually distributed over the plants. In general, P. rapae females began to lay eggs soon after being exposed to the experimental plants, and they deposited eggs on both the transgenic and the wild-type plant in more than $99.5 \%$ of all replicates. When plants were undamaged, ovipositing butterflies did not discriminate between 35S:ESP and Col-0 wild-type plants (Fig. 3): the average number of eggs laid per female did not differ between plant genotypes (Wilcoxon signed ranks test, $p>0.05, N=18$, Fig. 3 ). In $56 \%$ of the cases, the butterflies laid more eggs on the wild-type plant, while in $44 \%$ they deposited more eggs on the $35 \mathrm{~S}$ : ESP plant (sign test, $p>0.05, N=18$ ). However, the situation changed when plants were artificially damaged before being exposed to the butterflies. In this case, the butterflies significantly preferred to lay eggs on wild-type plants. In $81 \%$ of the cases, $P$. rapae laid more eggs on Col- 0 plants than on the 35S:ESP plants (sign test, $p<0.01, N=22$, Fig. 3). This trend is also reflected in the significantly larger number of eggs laid per female on wild-type plants (Fig. 3). Overall, when plants were damaged, the nitrileproducing $35 \mathrm{~S}: E S P$ plants were significantly less attractive for egg deposition by $P$. rapae than the isothiocyanateproducing wild-type Col-0.

Feeding Choice Experiments and Performance of $\mathrm{P}$. rapae The next step was to test whether caterpillars show the same preference as adult female butterflies. In a multiple-choice experiment, young $P$. rapae caterpillars were allowed to choose between three 35S:ESP plants and three Col-0 wild-type plants for $24 \mathrm{~h}$. All tested caterpillars fed on both the transgenic and the wild-type plants. There was no significant difference in the mean leaf area removed between 35S:ESP and wild-type plants (35S:ESP: $7.0 \pm 4.7$ $\mathrm{cm}^{2}$, Col-0: $6.1 \pm 3.6 \mathrm{~cm}^{2} ; N=18$; Mann-Whitney U test, $p$ $>0.05)$. Furthermore, we analyzed the performance of $p$. rapae caterpillars on the $35 \mathrm{~S}: E S P$ line and on wild-type plants. We recorded the larval weight after only 7 and 10

$\mathrm{N}$

No

response [\%]

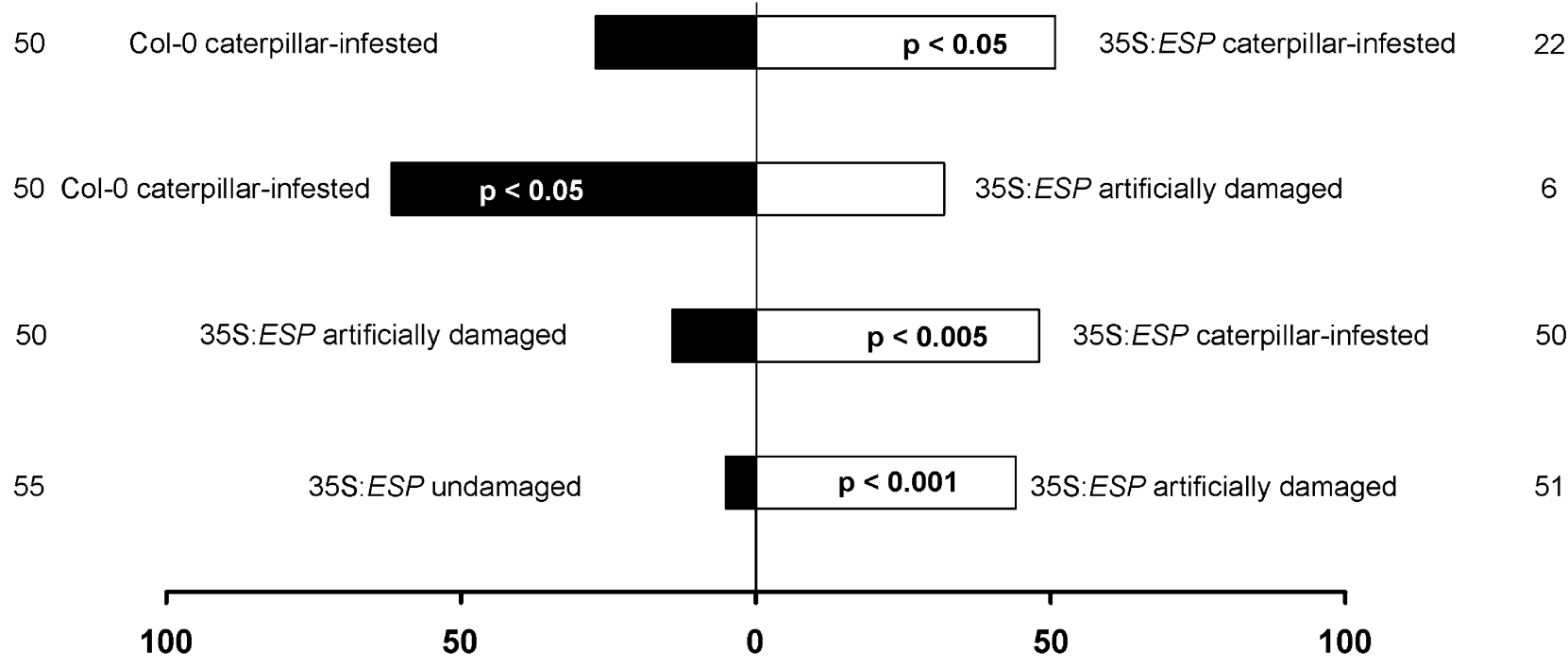

Fig. 2 Response of C. rubecula to odors of wild-type Arabidopsis Col-0 and transgenic 35S:ESP plants in a two-choice wind tunnel

experiment, or infested with P. rapae caterpillars for $24 \mathrm{~h}$. Parasitoids that did not make a choice were not included in the analysis. Choices setup. Plants were either intact, artificially damaged right before the 
Fig. 3 Oviposition by $P$. rapae on wild-type Arabidopsis Col-0 (black bars) and transgenic $35 \mathrm{~S}$ : ESP plants (white bars). Plants were either intact (left) or artificially damaged (right) before the experiment. Depicted is the mean number of eggs laid per female + standard error (analyzed using the Wilcoxon signed ranks test $(N=18$ with intact plants, $N=22$ with damaged plants)

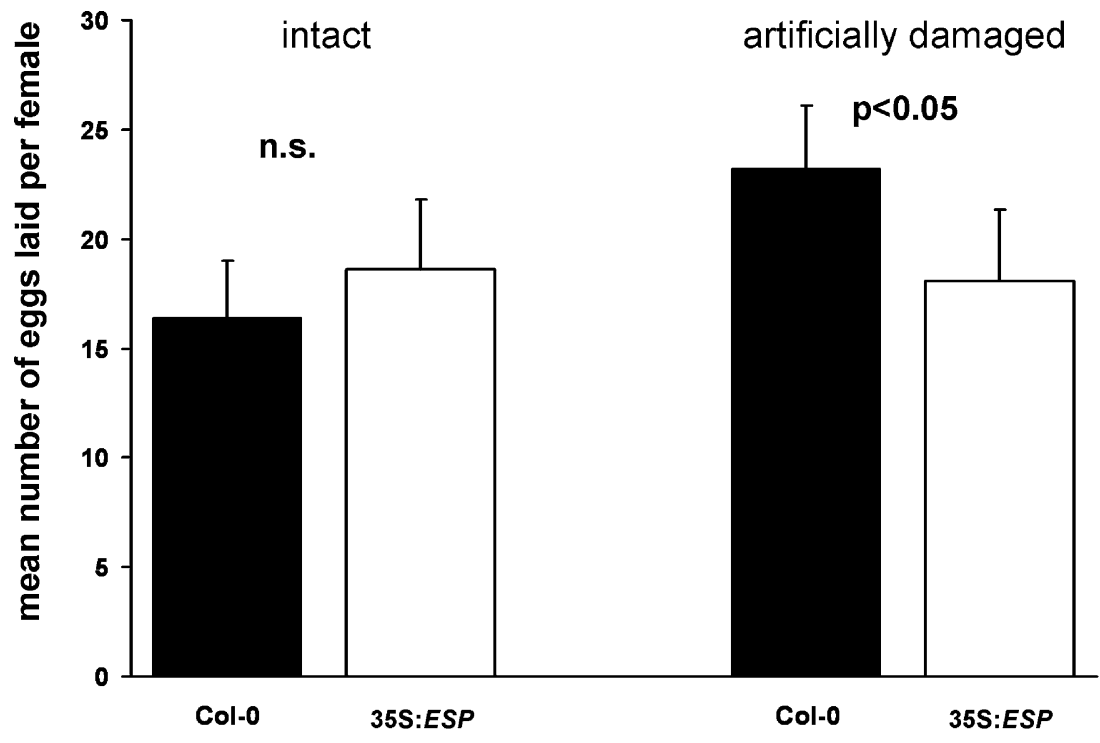

days as differences in food quality at this early stage have a particularly strong effect on caterpillar growth and development (J.J.A. van Loon, personal communication). However, larval weight of caterpillars did not significantly differ between the plant genotypes at day 7 or 10 (Table 1). Likewise, pupal weight, developmental time until pupation, and the total developmental time were not significantly different between $P$. rapae caterpillars that fed on either 35S:ESP or Col-0 wild-type plants (Table 1).

\section{Discussion}

Our study demonstrates that glucosinolate-containing plants can benefit from producing predominantly simple nitriles instead of isothiocyanates upon herbivore damage despite the fact that simple nitriles are less toxic than isothiocyanates to insect herbivores. The experiments described employed a transgenic 35S:ESP line that upon tissue maceration hydrolyzes glucosinolates to simple nitriles rather than to isothiocyanates as in Col-0 wild-type plants (Burow et al. 2006b). Despite the differences in glucosinolate hydrolysis, there were no significant alterations between 35S:ESP and wild-type plants in glucosinolate content and composition and myrosinase activity (Burow et al. 2006b). The nitrile-producing 35S:ESP plants attracted significantly more $C$. rubecula parasitoids than Col-0 wildtype plants when both were infested by P. rapae (Fig. 2).

Simple nitriles are not only released by plants but are also the predominant volatiles emitted by the frass of $P$. rapae caterpillars, which is known to attract $C$. rubecula from a distance (Agelopoulos and Keller 1994b; Geervliet et al. 1994; Agelopoulos et al. 1995; Wittstock et al. 2004).
Hence, nitrile-producing plants such as 35S:ESP plants may indicate the presence of feeding and defecating host larvae to reinforce the response of the parasitoids to $P$. rapaeinduced volatiles (Fig. 2). This explanation is supported by a previous study showing that a combination of volatiles from $P$. rapae-infested cabbage and $P$. rapae feces was more attractive to $C$. rubecula than those of caterpillarinfested plants alone depending on the infestation level (Agelopoulos et al. 1995). In the present study, significantly more parasitoids were attracted to infested 35S:ESP and infested Col-0 plants compared to artificially damaged $35 \mathrm{~S}$ : ESP plants. This demonstrates that the volatile blend emitted upon herbivory, including plant volatiles and volatiles derived from the herbivore, is more attractive to C. rubecula than volatiles emitted from the plant after mechanical damage (Fig. 2). Volatile blends of mechanically damaged 35S:ESP plants are most likely dominated by green leaf volatiles and simple nitriles, whereas the blend of caterpillar-infested plants is more complex, including also terpenoids and methyl salicylate (Van Poecke et al. 2001; Burow et al. 2006b). Indeed, $C$. rubecula parasitoids show electroantennogram responses to terpenoids and methyl salicylate in addition to responses to green leaf volatiles (Smid et al. 2002), indicating that these compounds have an important role in attracting the parasitoids as well. That the attraction of parasitoids is beneficial to the reproductive fitness of $A$. thaliana was demonstrated previously (Van Loon et al. 2000).

Many parasitoids change their behavioral preference to certain infochemicals by associative learning of these odors after a rewarding experience, e.g., an oviposition (Turlings et al. 1993; Vet et al. 1995). Also, C. rubecula can learn associatively to respond to certain plant odors either after an oviposition experience or by simply having contact with 
Table 1 Performance of P. rapae on Arabidopsis Col-0 and 35S:ESP

\begin{tabular}{lccc}
\hline & Col-0 wt $(N=39)$ & $35 S: E S P(N=37)$ & Mann-Whitney $U$ test $(p$ value $)$ \\
\hline Larval weight on day $7[\mathrm{mg}]$ & $24 \pm 2.1^{\mathrm{a}}$ & $27 \pm 1.8$ & $>0.05$ \\
Larval weight on day $10[\mathrm{mg}]$ & $150 \pm 7.7$ & $157 \pm 5.8$ & $>0.05$ \\
Pupal weight [mg] & $146 \pm 2.1$ & $141 \pm 3.0$ & $>0.05$ \\
Time until pupation [d] & $12.3 \pm 0.2$ & $12.2 \pm 0.2$ & $>0.05$ \\
Total developmental time [d] & $19.4 \pm 0.2$ & $19.2 \pm 0.2$ & $>0.05$ \\
\hline
\end{tabular}

${ }^{a}$ Data are presented as means \pm standard error

host products. However, unlike the situation in the closely related parasitoid species Cotesia glomerata, learning in $C$. rubecula results in an increased behavioral response towards the learned odor but does not shift an innate preference towards another odor (Bleeker et al. 2006; Smid 2006). This is confirmed by results of our study because introducing the parasitoids into the wind tunnel on a hostdamaged leaf, alternating between a wild-type and a transgenic leaf, did not bias the subsequent choice to the leaf type they previously experienced. Moreover, giving $C$. rubecula females an oviposition experience in the presence of the odor of one of the two plant types would likely not result in a preference for that learned odor (Bleeker et al. 2006; Smid 2006).

$P$. rapae females laid significantly fewer eggs on mechanically damaged 35S:ESP plants than on mechanically damaged Col-0 wild-type plants. However, there was no preference when plants were undamaged suggesting that glucosinolate hydrolysis products rather than the glucosinolates themselves influenced plant acceptance by $P$. rapae (Fig. 3). De Vos et al. (2008) showed that ovipositing $P$. rapae preferred isothiocyanate-producing Arabidopsis Col0 plants over 35S:ESP plants, even when the plants were not damaged. Numerous studies have shown that the nonvolatile glucosinolates serve as oviposition stimulants for $P$. rapae and closely related species (overview given by Chew and Renwick 1995; Hern et al. 1996; Schoonhoven et al. 2005). However, given that most glucosinolate hydrolysis products are volatile, while the parent glucosinolates are not, the hydrolysis products might be important cues for $P$. rapae at an earlier stage of the host location process. In fact, isothiocyanates in particular are known to attract many specialist herbivorous species (reviewed by Wittstock et al. 2003) and even to stimulate oviposition (Renwick et al. 2006). On the other hand, only a few studies have demonstrated that nitriles attract herbivores, and in general these were less attractive than isothiocyanates (Pivnick et al. 1992; Bartlet et al. 1997; Smart and Blight 2000; De Vos et al. 2008). Whether the preference of $P$. rapae to oviposit on isothiocyanate-emitting wild-type plants is due to the repellent effect of nitriles or to the stimulating effect of isothiocyanates or both remains to be investigated. However, oviposition preference of $P$. rapae for isothiocyanate-emitting wild-type plants is likely to benefit the butterflies either because isothiocyanates would indicate the presence of a (glucosinolate-containing) host plant or because nitrile emission could indicate a host plant that is already infested with conspecific larvae. Butterflies that avoid laying eggs on already infested host plants should reduce intraspecific competition and parasitism (Thompson and Pellmyr 1991). In fact, P. rapae is known to avoid laying eggs on plants that are infested with conspecific larvae or that carry conspecific eggs (Rothschild and Schoonhoven 1977; Schoonhoven et al. 1990; Sato et al. 1999). Nitriles, acting as indicators of feeding and defecating larvae, may not only signify the presence of competitors but may also hint at increased levels of glucosinolates and other defense compounds in the host plant as a result of induction that have a negative influence on the performance of the offspring (e.g., Agrawal and Kurashige 2003; Mewis et al. 2005, 2006; Gols et al. 2008). Accordingly, cabbage plants that were treated with jasmonic acid, a key hormone involved in induced plant defense, received significantly fewer eggs from $P$. rapae than respective control plants (Bruinsma et al. 2007).

The preference of $P$. rapae to oviposit on plants emitting isothiocyanates is likely due to the fact that isothiocyanate release indicates a functioning glucosinolate-myrosinase system. As many herbivores are not as well adapted to the glucosinolate-myrosinase system, the preference for a glucosinolate-containing plant by $P$. rapae butterflies is one key to avoid interspecific competition. Our present results show that $P$. rapae performed just as well on the isothiocyanate-producing Col-0 wild-type as on the nitrileproducing 35S:ESP line. In contrast, generalist herbivores are known to perform significantly better on nitrile-producing plants vs. isothiocyanate-producing plants (Lambrix et al. 2001; Burow et al. 2006b). P. rapae butterflies thus may be able to use isothiocyanates to select competitor-sparse food plants for their offspring (De Vos et al. 2008). To recap, gravid $P$. rapae females foraging for suitable host plants may have a number of reasons to prefer isothiocyanate-producing vs. nitrile-producing plants as an oviposition site. The release of nitriles upon damage may signal a higher risk of interspecific and intraspecific competition, an increased chance of parasitism, and a poorer substrate for larval 
development. Alternatively, nitrile-producing plants might receive fewer eggs due to the lack of isothiocyanates as oviposition stimulus.

In summary, this paper has demonstrated that $A$. thaliana plants producing simple nitriles rather than isothiocyanates are better defended against the specialist herbivore, $P$. rapae, because of reduced oviposition and increased attraction of a specialist larval parasitoid. In contrast, isothiocyanate-emitting plants appear to be better defended against generalist herbivores. These findings provide a rationale for the existence of a polymorphism among $A$. thaliana ecotypes (Lambrix et al. 2001). The selective balance between these glucosinolate hydrolysis phenotypes may shift depending on the proportion of specialist to generalist herbivores present.

Acknowledgements Many thanks are due to Leo Koopman, Frans van Aggelen, and André Gidding for culturing the insects and the experimental farm of Wageningen University (Unifarm) for rearing the Brussels sprout plants. We also thank Rieta Gols for help with some experiments. The study was financially supported by the European Commission contract MC-RTN-CT-2003-504720 "ISONET", by a VICI grant (nr 865.03.002) from the Earth and Life Sciences Foundation, which is subsidized by the Netherlands Organization for Scientific Research and by the Max Planck Society.

Open Access This article is distributed under the terms of the Creative Commons Attribution Noncommercial License which permits any noncommercial use, distribution, and reproduction in any medium, provided the original author(s) and source are credited.

\section{References}

Agelopoulos, N. G., and Keller, M. A. 1994a. Plant-natural enemy association in the tritrophic system Cotesia rubecula-Pieris rapaeBrassicaceae (Cruciferae): II. Preference of $C$. rubecula for landing and searching. J. Chem. Ecol. 20:1735-1748.

Agelopoulos, N. G., and Keller, M. A. 1994b. Plant-natural enemy association in the tritrophic system, Cotesia rubeculaPieris rapae-Brassicaceae (Cruciferae): I. Sources of infochemicals. J. Chem. Ecol. 20:1725-1734.

Agelopoulos, N. G., Dicke, M., and Posthumus, M. A. 1995. Role of volatile infochemicals emitted by feces of larvae in hostsearching behavior of parasitoid Cotesia rubecula (Hymenoptera: Braconidae): a behavioral and chemical study. J. Chem. Ecol. 21:1789-1811.

Agerbirk, N., Müller, C., Olsen, C. E., and Chew, F. S. 2006. A common pathway for metabolism of 4-hydroxybenzylglucosinolate in Pieris and Anthocaris (Lepidoptera: Pieridae). Biochem. Syst. Ecol. 34:189-198.

Agrawal, A. A., and Kurashige, N. S. 2003. A role for isothiocyanates in plant resistance against the specialist herbivore Pieris rapae. J. Chem. Ecol. 29:1403-1415.

Alibadi, A., Renwick, J. A. A., and Whitman, D. W. 2002. Sequestration of glucosinolates by harlequin bug Murgantia histrionica. J. Chem. Ecol. 29:1749-1762.

ANDRÉASSON, E., and JøRGENSEN, L. B. 2003. Localization of plant myrosinases and glucosinolates, pp. 79-99, in J. T. Romeo (ed.).
Integrative Phytochemistry: From Ethnobotany to Molecular Ecology. Pergamon, Amsterdam.

BARTH, C., and JANDER, G. 2006. Arabidopsis myrosinases TGG1 and TGG2 have redundant function in glucosinolate breakdown and insect defense. Plant J. 46:549-562.

Bartlet, E., Blight, M. M., Lane, P., and Williams, I. H. 1997. The responses of the cabbage seed weevil Ceutorhynchus assimilis to volatile compounds from oilseed rape in a linear track olfactometer. Entomol. Exp. Appl. 85:257-262.

Bernardi, R., Negri, A., Ronchi, S., and Palmieri, S. 2000. Isolation of the epithiospecifier protein from oil-rape (Brassica napus ssp oleifera) seed and its characterization. FEBS Lett. 467:296-298.

Blande, J. D., Pickett, J. A., and Poppy, G. M. 2007. A comparison of semiochemically mediated interactions involving specialist and generalist Brassica-feeding aphids and the braconid parasitoid Diaeretiella rapae. J. Chem. Ecol. 33:767-779.

Bleeker, M. A. K., Smid, H. M., Steidle, J. L. M., Kruidhof, H. M., VAN LoON, J. J. A., and Vet, L. E. M. 2006. Differences in memory dynamics between two closely related parasitoid wasp species. Anim. Behav. 71:1343-1350.

Braby, M. F., and Trueman, J. W. H. 2006. Evolution of larval host plant associations and adaptive radiation in pierid butterflies. $J$. Evol. Biol. 19:1677-1690.

Bradburne, R. P., and Mithen, R. 2000. Glucosinolate genetics and the attraction of the aphid parasitoid Diaeretiella rapae to Brassica. Proc. R. Soc. Lond. Ser. B 267:89-95.

Bruinsma, M., VAN Dam, N. M., VAN LoOn, J. J. A., and Dicke, M. 2007. Jasmonic acid-induced changes in Brassica oleracea affect oviposition preference of two specialist herbivores. J. Chem. Ecol. 33:655-668.

Burow, M., Markert, J., Gershenzon, J., and Wittstock, U. 2006a. Comparative biochemical characterization of nitrileforming proteins from plants and insects that alter myrosinasecatalysed hydrolysis of glucosinolates. FEBS J. 273:2432-2446.

Burow, M., Müller, R., Gershenzon, J., and Wittstock, U. 2006b. Altered glucosinolate hydrolysis in genetically engineered Arabidopsis thaliana and its influence on the larval development of Spodoptera littoralis. J. Chem. Ecol. 32:23332349.

Chew, F. S., and Renwick, J. A. A. 1995. Host plant choice in Pieris butterflies, pp. 214-238, in R. T. Cardé, and W. J. Bell (eds.). Chemical Ecology of Insects 2. Chapman \& Hall, New York.

Degenhardt, J., Gershenzon, J., Baldwin, I. T., and Kessleer, A. 2003. Attracting friends to feast on foes: engineering terpene emission to make crop plants more attractive to herbivore enemies. Curr. Opin. Biotechnol. 14:169-176.

De Vos, M., Kriksunov, K. L., and Jander, G. 2008. Indole-3acetonitrile production from indole glucosinolates deters oviposition by Pieris rapae (white cabbage butterfly). Plant Physiol. 146:916-926.

FAHEY, J. W., ZalcmanN, A. T., and TAlalay, P. 2001. The chemical diversity and distribution of glucosinolates and isothiocyanates among plants. Phytochemistry 56:5-51.

Foo, H. L., Gronning, L. M., Goodenough, L., Bones, A. M., Danielsen, B. E., Whiting, D. A., and Rossiter, J. T. 2000. Purification and characterisation of epithiospecifier protein from Brassica napus: enzymic intramolecular sulphur addition within alkenyl thiohydroximates derived from alkenyl glucosinolate hydrolysis. FEBS Lett. 468:243-246.

Geervliet, J. B. F., Vet, L. E. M., and Dicke, M. 1994. Volatiles from damaged plants as major cues in long-range host-searching by the specialist parasitoid Cotesia rubecula. Entomol. Exp. Appl. 73:289-297.

Geervliet, J. B. F., Vet, L. E. M., and Dicke, M. 1996. Innate responses of the parasitoids Cotesia glomerata and C. rubecula 
(Hymenoptera: Braconidae) to volatiles from different plantherbivore complexes. J. Insect Behav. 9:525-538.

Giamoustaris, A., and Mithen, R. 1995. The effect of modifying the glucosinolate content of leaves of oilseed rape (Brassica napus ssp oleifera) on its interaction with specialist and generalist pests. Ann. Appl. Biol. 126:347-363.

GlantZ, S. A. 2005. Primer of Biostatistics. McGraw-Hill, New York.

Gols, R., RaAijmakers, C. E., Van Dam, N. M., Dicke, M., BUKOVINSZKY, T., and HARVEY, J. A. 2007. Temporal changes affect plant chemistry and tritrophic interactions. Basic Appl. Ecol. 8:421-433.

Gols, R., WAGENAAR, R., BUKOVInSZKY, T., VAN DAM, N. M., Dicke, M., Bullock, J. M., and HarveY, J. A. 2008. Genetic variation in the defense chemistry of wild cabbage populations and its effects on native herbivores and their endoparasitoids. Ecology 89:1616-1626.

GRUBB, C. D., and ABEL, S. 2006. Glucosinolate metabolism and its control. Trends Plant Sci. 11:89-100.

HALKIER, B. A., and GershenzON, J. 2006. Biology and biochemistry of glucosinolates. Annu. Rev. Plant Biol. 57:303-333.

HARVEY, J. A., VAN DAM, N. M., and Gols, R. 2003. Interactions over four trophic levels: foodplant quality affects development of a hyperparasitoid as mediated through a herbivore and its primary parasitoid. J. Anim. Ecol. 72:520-531.

Harvey, J. A., Witjes, L. M. A., Benkirane, M., Duyts, H., and WAGENAAR, R. 2007. Nutritional suitability and ecological relevance of Arabidopsis thaliana and Brassica oleracea as foodplants for the cabbage butterfly, Pieris rapae. Plant Ecol. 189:117-126.

Hern, A., EDWARDS-JONES, G., and MCKINLAY, R. G. 1996. A review of the pre-oviposition behaviour of the small cabbage white butterfly, Pieris rapae (Lepidoptera: Pieridae). Ann. Appl. Biol. 128:349-371.

HiLKer, M., and MeINERS, T. 2002. Induction of plant responses to oviposition and feeding by herbivorous arthropods: a comparison. Entomol. Exp. Appl. 104:181-192.

HuAnG, X. P., and RenwiCK, J. A. A. 1994. Relative activities of glucosinolates as oviposition stimulants for Pieris rapae and $P$. napi oleracea. J. Chem. Ecol. 20:1025-1037.

Huang, X. P., Renwick, J. A. A., and Sachdev-Gupta, K. 1993. Oviposition stimulants and deterrents regulating differential acceptance of Iberis amara by Pieris rapae and P. napi oleracea. J. Chem. Ecol. 19:1645-1663.

Huang, X. P., Renwick, J. A. A., and Sachdevgupta, K. 1994. Oviposition stimulants in Barbarea vulgaris for Pieris rapae and $P$. napi oleracea-isolation, identification and differential activity. J. Chem. Ecol. 20:423-438.

KAISER, L., and CARDÉ, R. T. 1992. In-flight orientation to volatiles from the plant-host complex in Cotesia rubecula (Hym.: Braconidae): increased sensitivity through olfactory experience. Physiol. Entomol. 17:62-67.

Kazana, E., Pope, T. W., Tibbles, L., Bridges, M., Pickett, J. A., Bones, A. M., Powell, G., and Rossiter, J. T. 2007. The cabbage aphid: a walking mustard oil bomb. Proc. R. Soc. Lond. Ser. B 274:2271-2277.

KIM, J. H., and JANDER, G. 2007. Myzus persicae (green peach aphid) feeding on Arabidopsis induces the formation of a deterrent indole glucosinolate. Plant J. 49:1008-1019.

KLIEBENSTEIN, D. J. 2004. Secondary metabolites and plant/environment interactions: a view through Arabidopsis thaliana tinged glasses. Plant Cell Environ. 27:675-684.

Kliebenstein, D., Pedersen, D., BARKer, B., and Mitchell-Olds, T. 2002. Comparative analysis of quantitative trait loci controlling glucosinolates, myrosinase and insect resistance in Arabidopsis thaliana. Genetics 161:325-332.
Kliebenstein, D. J., Kroymann, J., and Mitchell-Olds, T. 2005. The glucosinolate-myrosinase system in an ecological and evolutionary context. Curr. Opin. Plant Biol. 8:264-271.

Lambrix, V., Reichelt, M., Mitchell-Olds, T., Kliebenstein, D. J., and GERSHENZON, J. 2001. The Arabidopsis epithiospecifier protein promotes the hydrolysis of glucosinolates to nitriles and influences Trichoplusia ni herbivory. Plant Cell 13:2793-2807.

LI, Q., Eigenbrode, S. D., Stringam, G. R., and Thiagarajah, M. R. 2000. Feeding and growth of Plutella xylostella and Spodoptera eridania on Brassica juncea with varying glucosinolate concentrations and myrosinase activities. J. Chem. Ecol. 26:2401-2419.

Mewis, I., Appel, H. M., Hom, A., Raina, R., and Schultz, J. C. 2005. Major signaling pathways modulate Arabidopsis glucosinolate accumulation and response to both phloem-feeding and chewing insects. Plant Physiol. 138:1149-1162.

Mewis, I., Tokuhisa, J. G., Schultz, J. C., ApPel, H. M., Ulrichs, C., and GERSHENZON, J. 2006. Gene expression and glucosinolate accumulation in Arabidopsis thaliana in response to generalist and specialist herbivores of different feeding guilds and the role of defense signaling pathways. Phytochemistry 67:2450-2462.

Miles, C. I., Del CAmpo, M. L., and Renwick, J. A. A. 2005. Behavioral and chemosensory responses to a host recognition cue by larvae of Pieris rapae. J. Comp. Physiol. A 191:147-155.

Müller, C., Agerbirk, N., Olsen, C. E., Boevé, J. L., Schaffner, U., and BRAKEFIELD, P. M. 2001. Sequestration of host plant glucosinolates in the defensive hemolymph of the sawfly Athalia rosae. J. Chem. Ecol. 27:2505-2516.

Murchie, A. K., Smart, L. E., and Williams, I. H. 1997. Responses of Dasineura brassicae and its parasitoids Platygaster subuliformis and Omphale clypealis to field traps baited with organic isothiocyanates. J. Chem. Ecol. 23:917-926.

PIVNICK, K. A. 1993. Response of Meteorus leviventris, (Hymenoptera: Braconidae) to mustard oils in field trapping experiments. $J$. Chem. Ecol. 19:2075-2079.

PIVnicK, K. A., LAmB, R. J., and ReED, D. 1992. Response of flea beetles, Phyllotreta spp, to mustard oils and nitriles in field trapping experiments. J. Chem. Ecol. 18:863-873.

Rask, L., Andreasson, E., EKBom, B., ERIKSSON, S., PontopPIDAN, B., and MEIJER, J. 2000. Myrosinase: gene family evolution and herbivore defense in Brassicaceae. Plant Mol. Biol. 42:93113.

Ratzka, A., Vogel, H., Kliebenstein, D. J., Mitchell-Olds, T., and Kroymann, J. 2002. Disarming the mustard oil bomb. Proc. Natl. Acad. Sci. U. S. A. 99:11223-11228.

Reddy, G. V. P., Holopainen, J. K., and Guerrero, A. 2002. Olfactory responses of Plutella xylostella natural enemies to host pheromone, larval frass, and green leaf cabbage volatiles. $J$. Chem. Ecol. 28:131-143.

RENwiCK, J. A. A. 2002. The chemical world of crucivores: lures, treats and traps. Entomol. Exp. Appl. 104:35-42.

Renwick, J. A. A., Haribal, M., Gouinguene, S., and Stadler, E. 2006. Isothiocyanates stimulating oviposition by the diamondback moth, Plutella xylostella. J. Chem. Ecol. 32:755-766.

RothsCHILD, M., and SCHOONHOVEN, L. M. 1977. Assessment of egg load by Pieris brassicae (Lepidoptera: Pieridae). Nature 266:352-355.

Sato, Y., Yano, S., Takabayashi, J., and Ohsaki, N. 1999. Pieris rapae (Lepidoptera: Pieridae) females avoid oviposition on Rorippa indica plants infested by conspecific larvae. Appl. Entomol. Zool. 34:333-337.

Schoonhoven, L. M., Beerling, E. A. M., BraAksma, R., and VANVUGT, Y. 1990. Does the imported cabbageworm, Pieris rapae, use an oviposition deterring pheromone? J. Chem. Ecol. $16: 1649-1655$. 
Schoonhoven, L. M., VAn Loon, J. J. A., and Dicke, M. 2005. Insect-Plant Biology. Oxford University Press, Oxford.

Smallegange, R. C., VAn Loon, J. J. A., Blatt, S. E., Harvey, J. A., AGERBIRK, N., and DiCKE, M. 2007. Flower versus leaf feeding by Pieris brassicae: glucosinolate-rich flower tissues are preferred and sustain higher growth rate. J. Chem. Ecol. 33:1831-1844.

SMART, L. E., and Blight, M. M. 2000. Response of the pollen beetle, Meligethes aeneus, to traps baited with volatiles from oilseed rape, Brassica napus. J. Chem. Ecol. 26:1051-1064.

SMID, H. M. 2006. Variation in learning of herbivory-induced plant odours by parasitic wasps, pp $89-103$, in M. Dicke, and W. Takken (eds.). Chemical Ecology: From Gene to Ecosystem, Springer, Dordrecht.

Smid, H. M., Van Loon, J. J. A., Posthumus, M. A., and Vet, L. E. M. 2002. GC-EAG-analysis of volatiles from Brussels sprouts plants damaged by two species of Pieris caterpillars: olfactory receptive range of a specialist and a generalist parasitoid wasp species. Chemoecology 12:169-176.

Snoeren, T. A. L., De Jong, P. W., and Dicke, M. 2007. Ecogenomic approach to the role of herbivore-induced plant volatiles in community ecology. J. Ecol. 95:17-26.

Thompson, J. N., and Pellmyr, O. 1991. Evolution of oviposition behavior and host preference in Lepidoptera. Annu. Rev. Entomol. 36:65-89.

Titayavan, M., and Altieri, M. A. 1990. Synomone-mediated interactions between the parasitoid Diaeretiella rapae and Brevicoryne brassicae under field conditions. Entomophaga 35:499-507.

TurlingS, T. C. J., WÄCKERS, F. L., VET, L. E. M., LEWIS, W. J., and Tumlinson, J. H. 1993. Learning of host-finding cues by hymenopterous parasitoids, pp. 51-78, in D. R. Papaj, and A. C. Lewis (eds.). Insect Learning: Ecological and Evolutionary PerspectivesChapman \& Hall, New York.

VAn LoON, J. J. A., BlaAKMEer, A., GriepinK, F. C., VAn BeeK, T. A., Schoonhoven, L. M., and DE GROOT, A. 1992. Leaf surface compound from Brassica oleracea (Cruciferae) induces oviposition by Pieris brassicae (Lepidoptera: Pieridae). Chemoecology 3:39-44.

Van Loon, J. J. A., De Boer, J. G., and Dicke, M. 2000. Parasitoidplant mutualism: parasitoid attack of herbivore increases plant reproduction. Entomol. Exp. Appl. 97:219-227.
VAN PoEcke, R. M. P. 2007. Arabidopsis-insect interactions, pp. 134, in C. Somerville, and E. M. Meyerowitz (eds.). The Arabidopsis BookAmerican Society of Plant Biologists, Rockville http://www.aspb.org/publications/Arabidopsis/.

Van Poecke, R. M. P., Posthumus, M. A., and Dicke, M. 2001. Herbivore-induced volatile production by Arabidopsis thaliana leads to attraction of the parasitoid Cotesia rubecula: chemical, behavioral, and gene-expression analysis. J. Chem. Ecol. 27:1911-1928.

Vergara, F., Svatos, A., Schneider, B., Reichelt, M., Gershenzon, J., and WitTSTOCK, U. 2006. Glycine conjugates in a lepidopteran insect herbivore - the metabolism of benzylglucosinolate in the cabbage white butterfly, Pieris rape. Chembiochem 7:1982-1989.

Vet, L. E. M., LewIS, W. J., and CARDÉ, R. T. 1995. Parasitoid foraging and learning, pp. $65-101$, in R. T. Cardé, and W. J. Bell (eds.). Chemical Ecology of Insects 2. Chapman and Hall, London.

Wheat, C. W., Vogel, H., Wittstock, U., Braby, M. F., Underwood, D., and Mitchell-OldS, T. 2007. The genetic basis of a plant insect coevolutionary key innovation. Proc. Natl. Acad. Sci. U. S. A. 104:20427-20431.

WitTstock, U., and Burow, M. 2007. Tipping the scales-specifier proteins in glucosinolate hydrolysis. IUBMB Life 59:744-751.

WitTstock, U., and HalkiER, B. A. 2002. Glucosinolate research in the Arabidopsis era. Trends Plant Sci. 7:263-270.

Wittstock, U., Kliebenstein, D. J., LAmbrix, V., Reichelt, M., and Gershenzon, J. 2003. Glucosinolate hydrolysis and its impact on generalist and specialist insect herbivores, pp 101-125, in J. T. Romeo (ed.). Integrative Phytochemistry: From Ethnobotany to Molecular Ecology. Pergamon, Amsterdam.

Wittstock, U., Agerbirk, N., Stauber, E. J., Olsen, C. E., Hippler, M., Mitchell-Olds, T., Gershenzon, J., and Vogel, H. 2004. Successful herbivore attack due to metabolic diversion of a plant chemical defense. Proc. Natl. Acad. Sci. U. S. A. 101:4859-4864.

Zhang, Z. Y., OBER, J. A., and KliebensteIn, D. J. 2006. The gene controlling the quantitative trait locus EPITHIOSPECIFIER MODIFIERI alters glucosinolate hydrolysis and insect resistance in Arabidopsis. Plant Cell 18:1524-1536. 